Bayero Journal of Pure and Applied Sciences, 10(1): 311 - 317

ISSN 2006 - 6996

\title{
CORROSION INHIBITION OF MILD STEEL USING ALKALOIDS AND TANNINS EXTRACTS OF Jatropha curcas IN ACIDIC MEDIA
}

\author{
"Rukaiyat, M. Said, Abubakar, G. Salisu and Fatima, M. Kntapo \\ Department of Applied Science, Kaduna Polytechnic, Nigeria \\ *Correspondence author: mrukaiya3@gmail.com
}

\begin{abstract}
Corrosion inhibition of mild steel in $0.5 \mathrm{M} \mathrm{H}_{2} \mathrm{SO}_{4}$ by the total alkaloids and tannins extracted from Jatropha curcas stem bark was investigated using gravimetric method at $303 \mathrm{~K}$. The results showed that it contains $1.66 \%$ alkaloids and $1.53 \%$ tannins, these phytocompounds were found to inhibit corrosion process of mild steel in the test solutions and the inhibition efficiency depends on the concentration of alkaloids and tannins as well as the exposure time. The adsorption of both alkaloids and tannins on the mild steel was found to obey the Temkin and Langmuir adsorption isotherms and this suggested that the inhibitor molecules have been spontaneously adsorbed onto the surface of mild steel through a physical adsorption mechanism. The inhibition efficiency is markedly higher in addition of alkaloid extracts when compared with that of tannins extracts. Corrosion inhibition is attributed to the spontaneous physical adsorption of the plant constituents on the surface of the mild steel. Keywords: Alkaloids, Corrosion, Inhibition, Mild steel, Tannins
\end{abstract}

\section{INTRODUCTION}

Corrosion is the destructive attack of a metal by chemical or electrochemical reaction with its environment, the corrosion of iron or iron base alloys with formation of corrosion products consisting largely of hydrous ferric oxide(Winston and Herbat, 2008). Mild steel is an alloy of iron containing small amounts of carbon 0.1-0.25\%, strong and tough (Collins, 1998).Beside carbon, there are many elements that form part of steel alloy such as chromium, manganese, tungsten and vanadium. When steel is exposed to an industrial atmosphere, reacts to form the reaction product rust of approximate composition $\mathrm{Fe}_{2} \mathrm{O}_{3} . \mathrm{H}_{2} \mathrm{O}$ (Loto, 2011). Corrosion is one of the major problems that must be confronted for the safety of our environment and for economic reasons. It occurs in various mechanical, metallurgical, biochemical and medical engineering appliances and more specifically in the design of a much more varied number of mechanical parts which equally vary in size, functionality and useful lifespan (Thompson et al., 2007). Several efforts have been made using corrosion preventive practices and the use of green corrosion inhibitors is one of them (Ashassi-sorkhabi et al., 2008). In line with the emerging concept of "Green Chemistry" and the related principles of 'Less hazardous synthesis,' therefore, the use of green inhibitors for the control of corrosion of metals ( Loto, 2011) and alloys which are in contact with aggressive environment is an accepted and growing practice (Taylor and Raja, 2007; Khalid and
Amin, 2009). Plant is one of the great chemical factories which can supply us with the chemicals required to inhibit the corrosion process, since most naturally occurring substances are safe and can be extracted by simple and cheap procedures (Taylor and Raja, 2007). An inhibitor is a chemical substance that, when added in small concentration to an environment, it effectively decreases corrosion rate(Winston and Herbat, 2008). The mechanism of action of inhibitors involve formation of a thin film passivation layer on the surface of the material that hinders access of the corrosive substances to the metal surface, thereby inhibiting either the oxidation or reduction part of the redox corrosion system or scavenging the dissolved oxygen. In acid medium, nitrogen-base materials and their derivatives, sulphur-containing compounds, aldehydes, thioaldehydes, acetylenic compounds, and various alkaloids, for example, papaverine, strychnine, quinine, and nicotine are used as inhibitors. In neutral media, benzoate, nitrite, chromate, and phosphate act as good inhibitors (Malik et al., 2011 ;Ebenso, 2004). Some investigations have in recent times been made into the corrosion inhibiting properties of natural products of plant origin and have been found to generally exhibit good inhibition efficiencies (Okafor and Ebenso, 2007). The yield of these natural products as well as the corrosion inhibition abilities of the plant extracts vary widely depending on the part of the plant and its location. 
Special Conference Edition, November, 2017

Of importance also, is the specificity of corrosion inhibiting compounds. A compound that is effective in a certain medium with a given metal may be ineffective for the same metal in another medium (Okafor et al., 2005). Many important researches have been reported on phyto compounds corrosion inhibition activities from various plants species. These include the use of henna, olive, shirshzallouh, vanillin, natural honey, khella, onion, Ficus, opuntia, many oils extracted from different parts of plants (Emeka, 2008, 2009; Ebenso et al., 2008).Many of these naturally occurring substances proved their ability to act as corrosion inhibitors for the corrosion of different metals and alloys in different aggressive media. This paper is focused on the inhibitive properties of alkaloids and tannins extracts of Jatropha curcas on the corrosion of mild steel in acidic media.

\section{MATERIALS AND METHODS}

\section{Collection and Identification of Sample}

Sample of stem bark of Jatropha curcas plant was collected from Afaka area of the Nigerian Defence Academy, Kaduna, Nigeria. Identified and authenticated by Mr Yahaya Abdullahi of Botany section, Department of Biological Sciences, Nigerian Defence Academy, Kaduna, Nigeria. The voucher specimen was deposited in the Herbarium. Mild steel was collected fromPanteka market, Kaduna, Nigeria.

\section{Sample Preparation}

The stem bark of Jatropha curcas plant was carefully removed and oven dried at $40{ }^{\circ} \mathrm{C}$ for 2 hours and left for 2 days to air dry( Loto, 2011). The dried sample was pulverized using a wood mill machine. The pulverized sample was weighed and preserved for hot continuous extraction.

Phytochemical analysis of the extract of stem bark of Jatropha curcas plant was carried out according to the method reported by (Eddy and Ebenso, 2008).

\section{Total Alkaloids Extraction}

Total alkaloids extracts was extracted from the stem bark of Jatropha curcas according to method described by Garba and Okeniyi (2012). Total Tannins Extraction

Total Tanninsextracts was extracted from the stem bark of Jatrophacurcas according to method reported by Faten, et al (2014).

Preparation of Mid Steel Sample

The nominal percent of mild steel used in this study is Carbon (0.19), silicon (0.25), Mn (0.64), $\mathrm{S}$ (0.05), $\mathrm{P}$ (0.06), Ni (0.09), Cr (0.08), Mo $(0.02)$, and $\mathrm{Cu}(0.27)$, the rest been Fe. The bar was cut into various rectangular pieces of coupons with dimensions $4 \times 2 \times 0.65 \mathrm{~cm}$. The test specimen was washed using a wire brush; polished with silicon carbide abrasive paper of 240, 320and 400 grits; polished to 1 micron and thoroughly cleaned and rinsed in ultrasonic cleaner, dried and kept in desiccators for further use(Loto, 2011).

Preparation of test media with the extracts The alkaloids and tannins extracts of the plant was used in the preparation of the test solutions by dissolving $0.1,0.2,0.3,0.4$ and 0.5 $\mathrm{g}$ of the alkaloid and tannins extracts differently in $1 \mathrm{~L}$ of $0.5 \mathrm{M} \mathrm{H} \mathrm{H}_{4}$. This correspond to the concentrations of $0.1,0.2$, $0.3,0.4$ and $0.5 \mathrm{~g} / \mathrm{L}$, while the blank medium without extract is made up of only $1 \mathrm{~L}$ of $0.5 \mathrm{M}$ of $\mathrm{H}_{2} \mathrm{SO}_{4}$ (Loto, 2011).

\section{Weight Loss Experiment}

Previously weighed test specimens of mild steels were totally immersed in each of the test media contained in a $250 \mathrm{~cm}^{3}$ beaker for 25days. The beaker was inserted into a water bath maintained at a temperature of 303K.

Experiment was performed with acid test media in which some had the solution extract added. Test specimen were taken out of the test media every 5days, washed with distilled water, rinsed with methanol, air dried and re weighed. The difference in the weight before the experiment and after the experiment were used as to determine the weight loss(Loto, 2011).

\section{RESULTS AND DISCUSSION}

The results obtained from phytochemical screening and extraction shows the presence of alkaloids and tannins with the percentage yields of the total alkaloids and Tannins extracted from the stem bark of Jatropha curcas to be $1.66 \%$ and $1.53 \%$ respectively. Inhibition of total alkaloids and Tannins extracted from Jatropha curcas showed that inhibition rates increases with increase in their concentration in the $\mathrm{H}_{2} \mathrm{SO}_{4}$ medium. Plot of weight loss versus time of exposure and calculated corrosion rate against time of exposure were used as the percentage inhibitor efficiency. Figures 1 and2 below shows the variation of weight loss with time of exposure for the corrosion of mild steel in $0.5 \mathrm{M} \mathrm{H}_{2} \mathrm{SO}_{4}$ acid containing various concentrations of alkaloids and Tannins extract of J. curcasat303 $\mathrm{K}$. It can be seen that weight loss of mild steel increases with increase in the period of contact but decreases with increase in concentration of alkaloids extracts indicating that the rate of corrosion of mild steel increases as the period of contact increases and that alkaloids extract inhibited the corrosion of mild steel in $\mathrm{H}_{2} \mathrm{SO}_{4}$ medium. 
At the $25^{\text {th }}$ day, the weight loss of the mild steel increased to $2.8 \mathrm{~g}$ which is very close to that of the sample without extract i.e $3.2 \mathrm{~g}$ (figure 1).Similar trend was observed in all

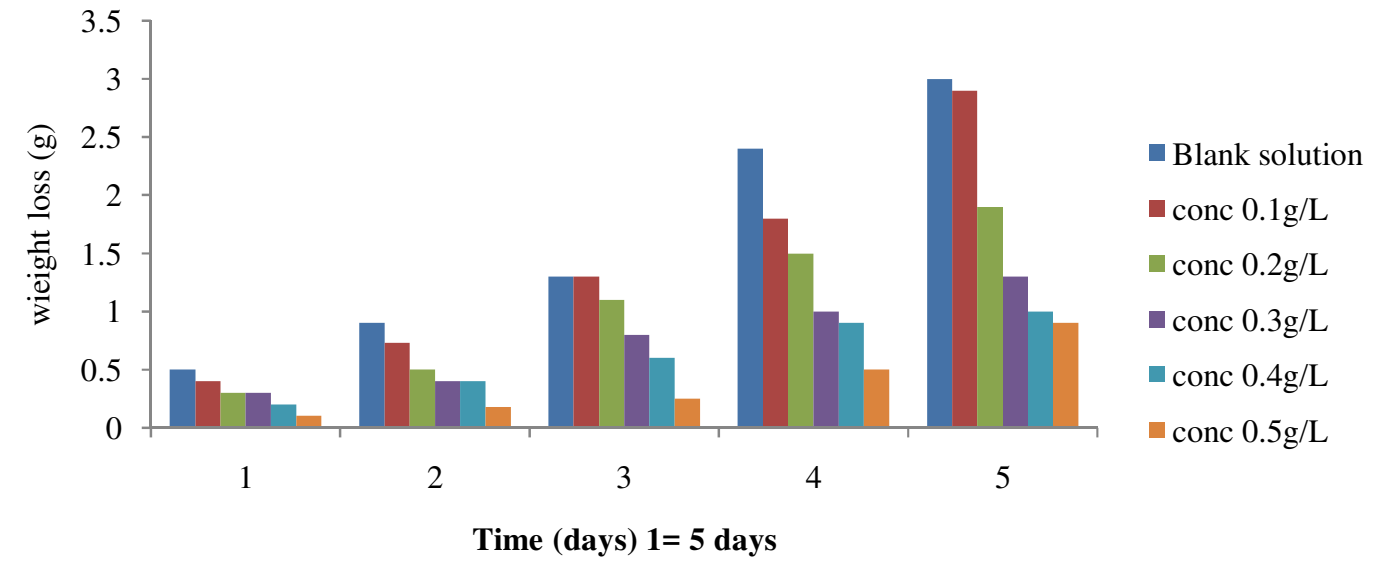

Fig 1: Results of weight loss experiment of Alkaloid extracts from Jatropha curcas in $\mathrm{H}_{2} \mathrm{SO}_{4}$ medium at $303 \mathrm{~K}$.

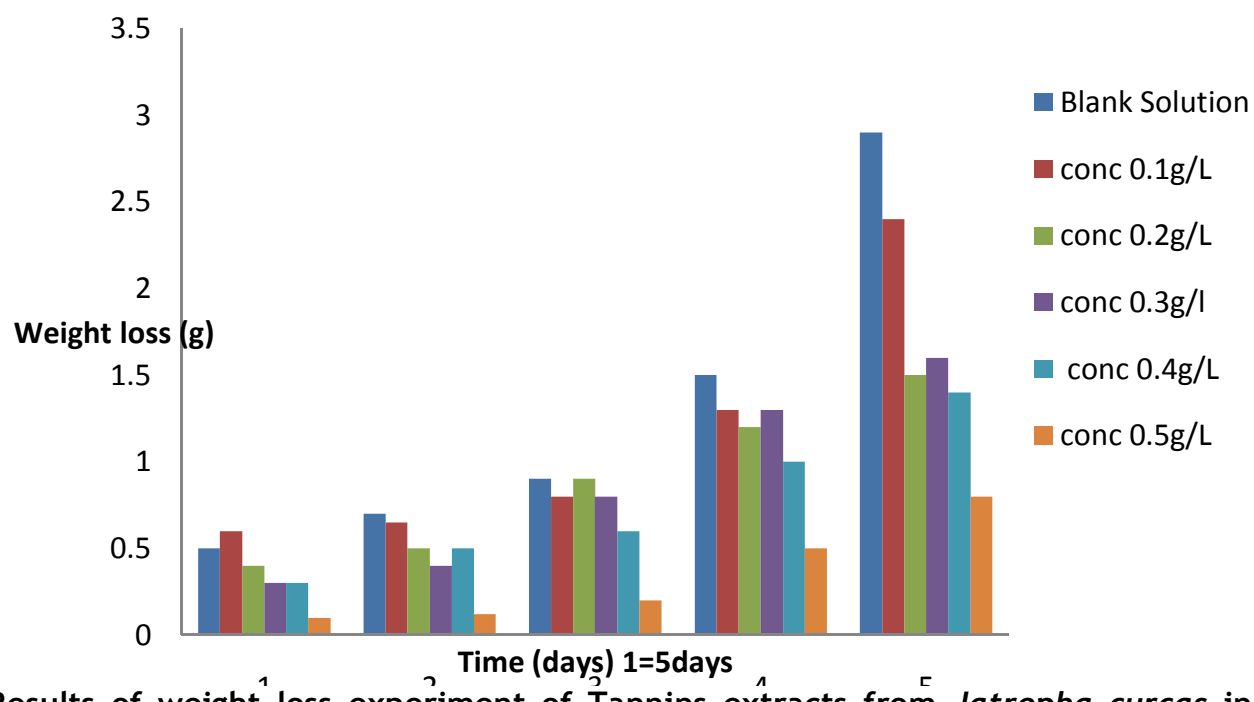

Fig 2: Results of weight ${ }^{1}$ loss experiment of Tannins extracts from Jatropha curcas in $\mathrm{H}_{2} \mathrm{SO}_{4}$ medium at $303 \mathrm{~K}$.

For the tannins extract, in (figure 2) similar trends was observed except that values of weight loss were relatively lower than those obtained when alkaloids extracts were used at various concentrations. Figure 2 revealed that the corrosion rate increase with increase in the period of contact but decreases with increase in the concentration of tannins extract of the plant indicating that the rate of corrosion of mild steel in $\mathrm{H}_{2} \mathrm{SO}_{4}$ increases with increase in the period of contact but decreases with increase in the concentration of Tannins extract.

Values of corrosion rates of mild steel and inhibition efficiencies of plants extract of $J$. media of the experiments, thus the height in chart is corresponding to increase in weight loss with increase in period of contacts. 
Where $\mathrm{W}=$ weight loss $(\mathrm{g}), \mathrm{A}=$ area of specimen $(\mathrm{cm})$ and $\mathrm{t}=$ period of immersion $(\mathrm{h})$ The adsorption of the Alkaloid and Tannins is through functional groups which the inhibitors interact with the metal surface. Their structural backbone contains additional functional groups that enhance the electronic bonding strength of the interacting group on the metal surface. Electron donating substituent increase inhibition by increasing the electron density of the anchoring group $(\mathrm{COOH}$ group); on the other hand, electronwithdrawing, substituent's decrease inhibition by decreasing the electron density. This result is in agreement with the findings reported on the use of Jatropha curcas whole extracts for corrosion inhibition of brass in $1 \mathrm{M} \mathrm{HCl}$ (Deepa, 2011), and also in agreement with the finding reported on alkaloid extract from Palicourea guiannensis plant as corrosion inhibitor for $C_{38}$ steel (Lebe et al., 2013).

Table 1: Alkaloids and Tannins Extracts of Jatropha curcas corrosion inhibition efficiency in $\mathrm{H}_{2} \mathrm{SO}_{4}$ medium at the $25^{\text {th }}$ day

\begin{tabular}{lllll}
\hline Extracts & $\begin{array}{l}\text { Concentration } \\
(\mathbf{g} / \mathrm{L})\end{array}$ & $\begin{array}{l}\text { Corrosion } \\
\text { Rate } \\
\left(\mathbf{g h -}^{-1} \mathrm{~cm}^{-2}\right)\end{array}$ & $\begin{array}{l}\text { xtracts } \\
\text { Inhibition } \\
\text { Efficiency (\%) }\end{array}$ & $\begin{array}{l}\text { Surface } \\
\text { coverage } \\
\boldsymbol{\Theta}\end{array}$ \\
\hline Alkaloids & $\mathbf{1 0 ^ { - 4 } )}$ & & $\mathbf{1 3}$ & 0.13 \\
& 0.1 & 5.01 & 27 & 0.27 \\
& 0.2 & 3.32 & 40 & 0.40 \\
& 0.3 & 3.13 & 50 & 0.50 \\
Tannins & 0.4 & 2.91 & 70 & 0.70 \\
& 0.5 & 1.66 & 20 & 0.03 \\
& 0.1 & 5.83 & 40 & 0.10 \\
& 0.2 & 5.01 & 60 & 0.36 \\
& 0.3 & 2.50 & 67 & 0.47 \\
\hline
\end{tabular}

The Temkin and Langmuir adsorption isotherm equation were used to deduced the adsorption characteristics of the inhibitors.

Temkin adsorption isotherm equation as: $\exp (-2 a \theta)=K C$ eqt3

Langmuir adsorption isotherm equation as: $c=\frac{1+a}{\theta K}$ eqt4

where $\Theta=$ degree of coverage, $a=$ an interaction parameter, taking into account the attraction $(a>0)$ or repulsion $(a<0)$ between the adsorbed species, $\mathrm{C}=$ concentration of the inhibitor in the electrolyte, and $\mathrm{K}=$ equilibrium constant of the adsorption process.

From Fig 3-4, the straight line plot is linear with a correlation coefficient; $R^{2}$ about 0.98 , indicates that the adsorption of both alkaloids and tannins on the mild steel obey both Langmuir and Temkin adsorption isotherms and this suggested that the inhibitor molecules have been spontaneously adsorbed onto the surface of mild steel through a physical adsorption mechanism. The result indicates that Temkin and Langmuir adsorption isotherms are valid for various extract concentrations of $\mathrm{J}$. curcas plant.
Temkin adsorption isotherm considers lateral interactions between adsorbed inhibitor molecules as well as those among inhibitor and water molecules, indicating that the inhibitor is displacing water molecules from the metal surface on the assumes that the adsorption heat of all molecules decreases linearly with the increase in coverage of the adsorbent surface, and that adsorption is characterized by a uniform distribution of binding energies, up to a maximum binding energy while Langmuir assumption of similar energy of adsorption sites, absorbent surface. It expresses with equation that is linear form. in a this equation by paying attention to the equal of amount of adsorption and repelling on surface (Piccin et al 2011;LjVracar and Drazic, 2002). With increasing corrosion of inhibitor, concentration inhibitor molecules probably start to desorbs due to interaction between the inhibiting molecules already adsorbed at the surface and those present in the solution. With increasing concentration of the inhibitor, the interactions become stronger, leading to secondary desorption 


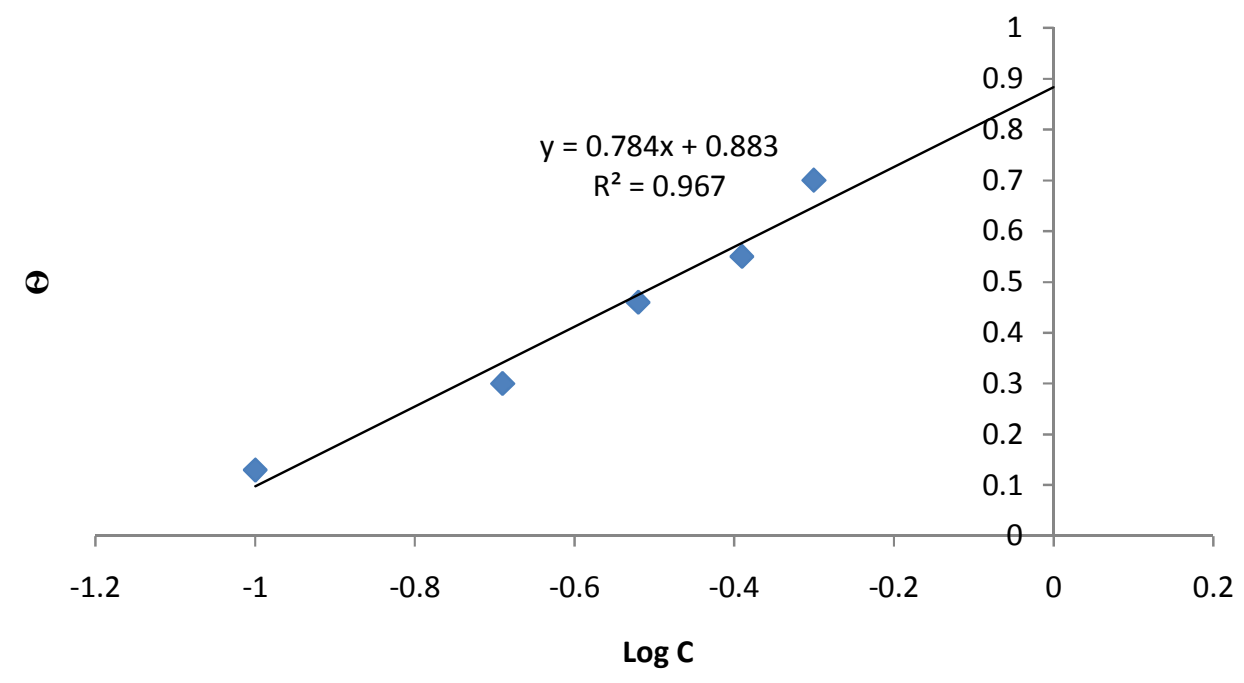

Fig 3a; Temkin adsorption isotherm for Alkaloids extracted from Jatropha curcas on mild steel in $\mathrm{H}_{2} \mathrm{SO}_{4}$ medium at $303 \mathrm{~K}$

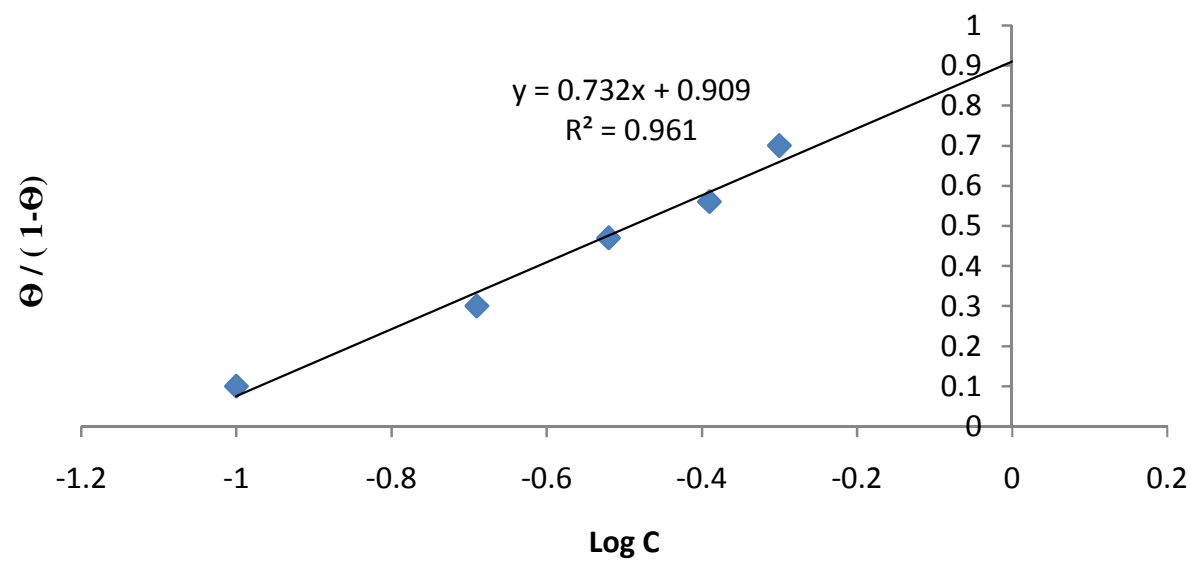

Fig 3b; Langmuir adsorption isotherm for Alkaloids extracted from Jatropha curcas on mild steel in $\mathrm{H}_{2} \mathrm{SO}_{4}$ medium at $303 \mathrm{~K}$

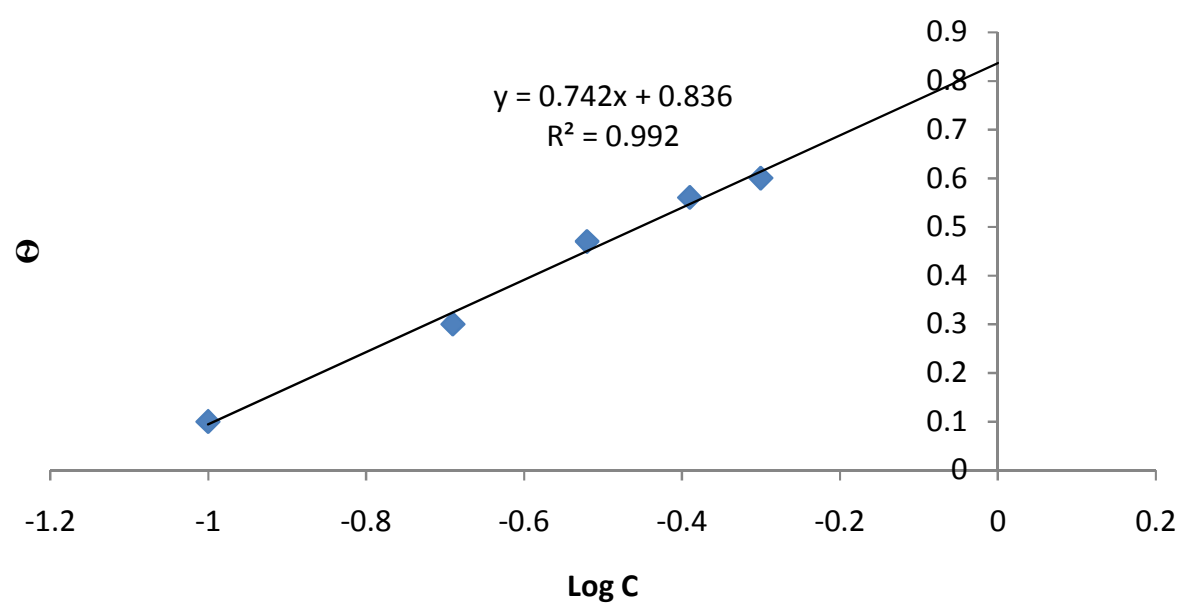

Fig 4a:Temkin adsorption isotherm for Tannins extracted from Jatropha curcas on mild steel in $\mathrm{H}_{2} \mathrm{SO}_{4}$ medium at $303 \mathrm{~K}$. 


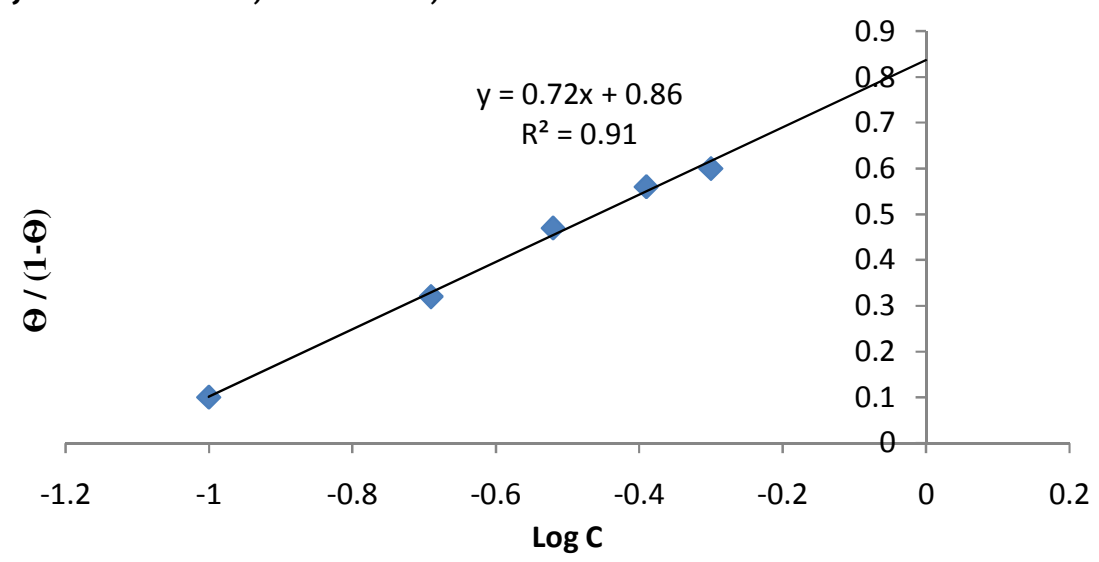

Figure 4b:Langmuir adsorption isotherm for tannins extracted from Jatropha curcas on mild steel in $\mathrm{H}_{2} \mathrm{SO}_{4}$ medium at $303 \mathrm{~K}$.

\section{CONCLUSION}

The gravimetric method was found to have proved the inhibitive nature of the alkaloids and tannins extracts on the corrosion of mild steel in $\mathrm{H}_{2} \mathrm{SO}_{4}$. The plant extracts were found to obey Temkinand Langmuir adsorption isotherms from the fit of experimental data. Comparison of the results with Temkin and Langmuir adsorption isotherm indicates that the extracted secondary metabolites forms strong

\section{REFERENCES}

Ashassi-sorkhabi H, Shaabani B, Aligholipour B, Seifzadeh D (2008). The effect of Schiff bases on the corrosion of aluminium in $\mathrm{HCl}$ solution. Appl. Surf. Sci. 252: 40394047.

Collins, English Dictionary - Complete and Unabridged (c) HarperCollins Publishers 1991, 1994, 1998, 2000, 2003.

Ebenso, E. E. (2004). Effect of methyl red and halide ions on the corrosion of aluminium in $\mathrm{H}_{2} \mathrm{SO}_{4}$. Part 2, Bull. Electrochem. 12: 551-559.

Ebenso, N. Eddy, A. Odiongenyi, (2008) Corrosion inhibition and adsorption properties of methacarbanol on mild steel in acidic medium, Portugaliae Electrochemica Acta, 27(1), 13-22. Eddy, N.O. and $\begin{aligned} & \text { (2008).Adsorption and inhibitive } \\ & \text { propenso, E. E. }\end{aligned}$ properties of ethanol extracts of Musa sapientum peels as a green corrosion inhibitor for mild steel in $\mathrm{H}_{2} \mathrm{SO}_{4}$, African J. Pure Appl. Chem., 2(6):046-054

Emeka E. Oguzie, (2008) Corrosion inhibitive effect and adsorption behaviours of Hibiscus sabdariffa on mild steel in acidic media, Portugaliae ElectrochemicaActa, .26,303-314,

Emeka E. Oguzie, (2009) Evaluation of some inhibitive effect of some plant extracts protective film on the surface of mild steel to conform with physical adsorption mechanisms. Use of the plant as a corrosion inhibitor will be of great socio-economic importance, therefore some direction for further research on this area may include Phytocompounds such as phenols, phenolic acid be investigated as they are reported to have great inhibitor properties. Studies on the plants should be expanded to cover additional media and other metals.

on the acid corrosion of mild steel, Corrosion Science, 50,.2993-2998,

Faten, M. Hanen Radh, K. andChedly, A. (2014). Total phenolic, flavonoid and tannin contents and antioxidant and antimicrobial activities of organic extracts of shoots of the plant Limonium delicatulum. Journal of Taibah University for Science 8 (3) 216224.

Garba, S.andOkeniyi S. O. (2012). Antimicrobial activities of total alkaloids extracted from some Nigerian medicinal plants.Journal of Microbiology and Antimicrobials Vol. 4(3), : 60-63.

Khaled, K. F and Amin, M. A. (2009) Electrochemical and molecular dynamics simulation studies on the corrosion inhibition of aluminum in molar hydrochloric acid using some imidazole derivatives. Journal of Applied Electrochemistry, 39 (12)25532568.

Lebe, A. N; Israel, O. O, Onyinyechi, C. N;Nneka, D. E; and Wisdom, J. O.(2013). Adsorption and Corrosion Inhibtion of Gnetum Africana Leaves Extract on Carbon Steel, International Journal of Materials and Chemistry 3(1): 10-16 DOI: 10.5923 
Special Conference Edition, November, 2017

Loto, C.A. ( 2011). The effect of Mango bark and leaves extract solution additive on the corrosion inhibition of mild steel in dilute $\mathrm{H}_{2} \mathrm{SO}_{4}$. International Journal of Recent Scientific Research, 2 (6):173 178,

Malik,L..Serra, Z. R., Montemor, M. F., and Ferreira, M.G.S (2011).Oxide nanoparticle reservoirs for storage and prolonged release of the corrosion inhibitors, Electrochemistry Communications, 7(8): 836-840.

Okafor, P. C., Osabor, V. I. and E. E. Ebenso, (2007) "Eco-friendly corrosion inhibitors: Inhibitive action of ethanol extracts of Garcinia kola for the corrosion of mild steel in $\mathrm{H}_{2} \mathrm{SO}_{4}$ solutions," Pigment and Resin Technology, vol. 36, no. 5, pp. 299-305.

Piccin, J. S; Dotto, G. L; and Pinto, L. A. (2011).Adsorption isotherms and thermochemical data of FD\&C Red $n^{\circ}$
40 binding by Chitosan. Braz. J. Chem. Eng. .28 (2) São Paulo

Taylor and Raja, P. B. ( 2007)Corrosion inhibition of mild steel by Datura metel in acidic medium, Pigment and Resin Technology, 34 (6): 327-331,

Thompson, P., Tandel,B. and Oza, B. N., (2007) Performance of some dyestuffs as inhibitors during corrosion of mild-steel in binary acid mixtures $(\mathrm{HCl}+$ $\mathrm{HNO}_{3}$ ), Journal of the Electrochemical Society of India, 49: 49-128,

Vraca, M. Lj.D and Drazic, D.M. (2002).Adsorption and corrosion inhibitive properties of some organic molecules on iron electrode in sulfuric acid. Corros. Sci. 44, 1669-1680

Winston, R. R. and Herbert H. U. (2008) Corrosion and corrosion control: an introduction to corrosion science and engineering 4th ed. John Wiley \& Sons, Inc., Hoboken New Jersey, pp 303-316 